\title{
Incarcerated Umbilical Hernia in a Cirrhotic With Caput Medusa- Role of Preoperative Tips, a Case Report
}

\author{
Apurva Pande ${ }^{1}$, Kishore BG ${ }^{2}$, Amar Mukund ${ }^{3}$ and Shasthry SM*1 \\ ${ }^{1}$ Department of Hepatology and Transplant Medicine, Institute of Liver and Biliary Sciences, India \\ ${ }^{2}$ Department of Hepato-Pancreatico-Biliary Surgery, Institute of Liver and Biliary Sciences, India \\ ${ }^{3}$ Department of Interventional Radiology, Institute of Liver and Biliary Sciences, India
}

Submission: July 11, 2017; Published: July 26, 2017

*Corresponding author: Shasthry SM, DM Hepatology; Assistant Professor, Department of Hepatology and Transplant Medicine, Institute of Liver and Biliary Sciences, D-1,Vasant Kunj, New Delhi, India, Email: shasthry@gmail.com

\begin{abstract}
A 42 year old male known to have hepatitis B related chronic liver disease decompensate with refractory as cites, hydrothorax presented with an incarcerated umbilical hernia containing omentum and an uncomplicated right inguinal hernia. Physical examination was remarkable for the presence of caput medusae and multiple collaterals. Computed tomography showed against reanalyzed paraumbilical vein which served as an afferent pathway to a tuft of dilated tortuous periumbilical collaterals which drained into the common femoral vein via the left sided inferior epigastric veins. He underwent Trans jugular intrahepatic porto-systemic shunt. Two weeks later, the collaterals had reduced significantly in size and he underwent repair of both hernias electively without any blood transfusion. The patient remains well on follow up with the abdominal wall collaterals having disappeared and he has been listed for liver transplantation.
\end{abstract}

\section{Introduction}

Hernias of the abdominal wall that arise from $3 \mathrm{~cm}$ above to $3 \mathrm{~cm}$ below the umbilicus are defined as umbilical hernia as per the European Hernia Society Classification. [1] 20\% of the patients of cirrhosis complicated with as cites have umbilical hernia $[2,3]$. As the intra abdominal pressure is quite high in these patients there is always a tendency of these hernias to enlarge rapidly and complicate [4]. Umbilical hernia occur more frequently in male cirrhotics in contrast to the general population where female gender and obesity are the major risk factors $[1,4]$. Treatment of cirrhotics with umbilical hernia has been controversial [5-8]. These patients were treated expectantly in the past due to an increased rate of complications and recurrence $[5,6]$. Expectant management could lead to complications like leaking of ascitic fluid, peritonitis, evisceration, incarceration of the content of hernial sac [7]. Many recent studies have shown that the results of surgical repair depend on the grade of as cites and liver function [9-12]. It has been shown that elective repair of umbilical hernia is safe and effective in patients whom as cites has been controlled [12]. Timing, indication and surgical aspects of hernia repair remain controversial in these subjects [6-10]. Use of a mesh in laparoscopic surgery is still a major area of discussion [13-15].

\section{Case}

A 42 year old male known to have hepatitis B related chronic liver disease (CTP score-11/15 MELD score 19 MELD Na-19), decompensated with refractory as cites, hydrothorax presented with an incarcerated umbilical hernia containing omentum and an uncomplicated right inguinal hernia. Physical examination was remarkable for the presence of caput medusae and multiple collaterals (Figure 1). Computed tomography and trans-hepatic venogram showed a giant recanalised paraumbilical vein which served as an afferent pathway to a tuft of dilated tortuous periumbilical collaterals which drained into the common femoral vein via the left sided inferior epigastric veins (Figures 2A-2C). Surgeons initially refused to offer him hernia repair in view of multiple large collaterals. He underwent transjugular intrahepatic porto-systemic shunt (TIPS) along with coil embolization of the collateral. Two weeks later, the collaterals had reduced significantly in size and he underwent repair of both hernias electively without any blood transfusion (Figures 3A \& 3B). Peri-operative course was uneventful without any worsening of jaundice, asc ites or coagulopathy and was discharged on post operative day 8. He remains well on follow up of more than one year with the abdominal wall collaterals 
having disappeared and no ascites. He has been listed for liver transplantation.
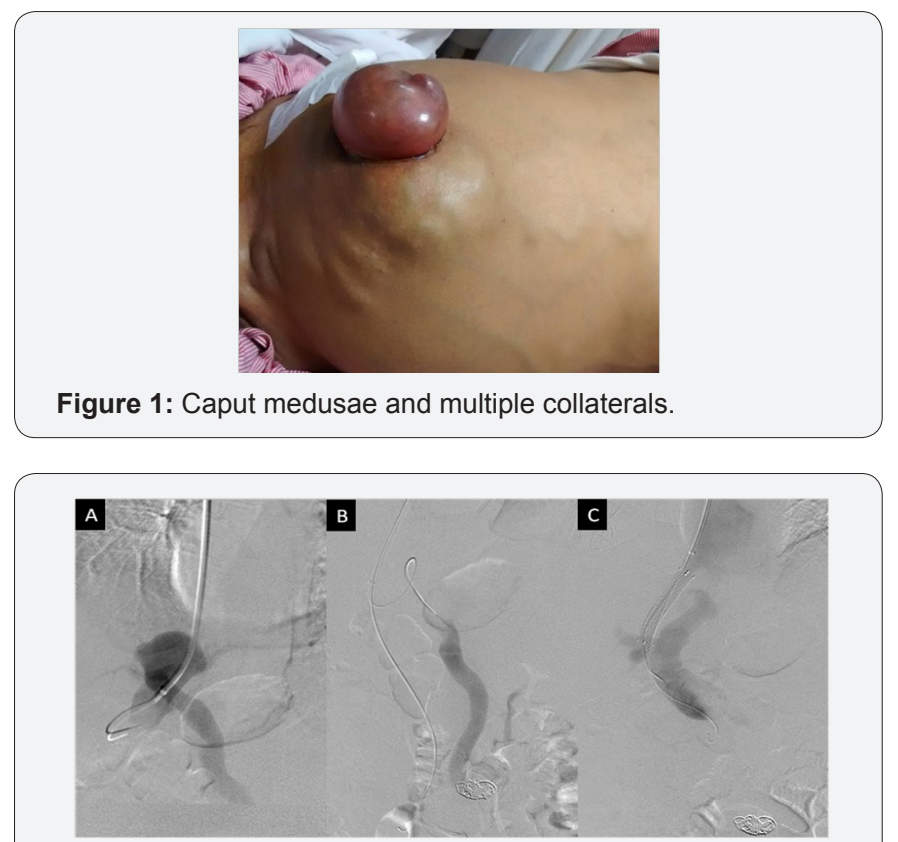

Figure 2A: Computed tomography showed a giant recanalised paraumbilical vein which served as an afferent pathway.

Figure 2B: Tuft of dilated tortuous periumbilical collaterals which drained into the common femoral vein via the left sided inferior epigastric veins

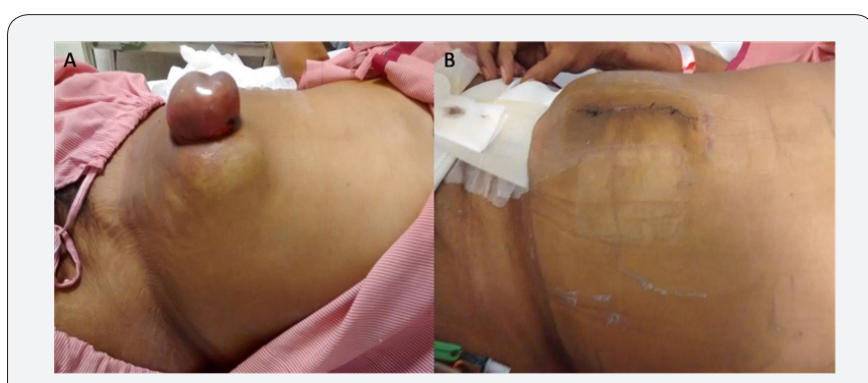

Figure 3A: Reduced collaterals

Figure 3B: Post operative image of the reduced umbilical hernia.

\section{Discussion}

The treatment of umbilical hernia in cirrhotics is quite challenging. Control of as cites forms the mainstay of treatment as this leads to reduced hernia recurrence and postoperative complications like wound dehiscence, infection, evisceration and peritonitis. Use of diuretics, paracentesis at regular intervals and transjugular intrahepatic port systemic shunt (TIPS) are often necessary to control as cites. TIPS done preoperatively in these patients may allow better control of as cites and in turn make them more amniable for herniorapphy. It has been shown that there should be a low threshold for placement of TIPS in these patients to reduce the chance of increased intraoperative bleed, preoperative worsening of liver functions, recurrence of ascites and hence the hernia and allow prolonged symptom free post operative period [16]. Our patient underwent TIPS pre operatively and this was followed by a herniorrhapy on day 12 Post TIPS with uneventful post operative recovery and good long term follow up. The use of measures like TIPS for portal venous decompression preoperatively has been supported by the fact that uncontrolled as cites increase the risk of postoperative complications and recurrence [17].

TIPS have been reported to be the most preferred method [17-20]. Caput medusse represent paraumbilical vein port systemic collateral vessels draining into body wall systemic veins. It's always better to decompress the caput medusse prior to the surgery to minimize the risk of intra and preoperative bleeding and post operative leak consequent to the reduced pressures.

\section{References}

1. Muysoms FE, Miserez M, Berrevoet F, Campanelli G, Champault GG, et al. (2009) Classification of primary and incisional abdominal wall hernias. Hernia 13: 407-414.

2. Chatzizacharias NA, Bradley JA, Harper S, Butler A, Jah A, et al. (2015) Successful surgical management of ruptured umbilical hernias in cirrhotic patients. World J Gastroenterol 21: 3109-3113.

3. Sarit C, Eliezer A, Mizrahi S (2003) Minimally invasive repair of recurrent strangulated umbilical hernia in cirrhotic patient with refractory ascites. Liver Transpl 9(6): 621-622.

4. Ammar SA (2010) Management of complicated umbilical hernias in cirrhotic patients using permanent mesh: randomized clinical trial. Hernia 14(1): 35-38.

5. Carbonell AM, Wolfe LG, DeMaria EJ (2005) Poor outcomes in cirrhosisassociated hernia repair: a nationwide cohort study of 32,033 patients. Hernia 9(4): 353-357.

6. Belghiti J, Durand F (1997) Abdominal wall hernias in the setting of cirrhosis. Semin Liver Dis 17(3): 219-226.

7. Marsman HA, Heisterkamp J, Halm JA, Tilanus HW, Metselaar HJ, Kazemier G (2007) Management in patients with liver cirrhosis and an umbilical hernia. Surgery 142(3): 372-375.

8. Gray SH, Vick CC, Graham LA, Finan KR, Neumayer LA, et al. (2008) Umbilical herniorrhapy in cirrhosis: improved outcomes with elective repair. J Gastrointest Surg 12(4): 675-681.

9. Choi SB, Hong KD, Lee JS, Han HJ, Kim WB, et al. (2011) Management of umbilical hernia complicated with liver cirrhosis: an advocate of early and elective herniorrhaphy. Dig Liver Dis 43(12): 991-995.

10. Cho SW, Bhayani N, Newell P, Cassera MA, Hammill CW, et al. (2012) Umbilical hernia repair in patients with signs of portal hypertension: surgical outcome and predictors of mortality. Arch Surg 147: 864-869.

11. Saleh F, Okrainec A, Cleary SP, Jackson TD (2015) Management of umbilical hernias in patients with ascites: development of a nomogram to predict mortality. Am J Surg 209(2): 302-307.

12. Eker HH, van Ramshorst GH, de Goede B, Tilanus HW, Metselaar HJ, et al. (2011) A prospective study on elective umbilical hernia repair in patients with liver cirrhosis and ascites. Surgery 150(3): 542-546.

13. Hassan AM, Salama AF, Hamdy H, Elsebae MM, Abdelaziz AM, et al. (2014) Outcome of sublay mesh repair in non-complicated umbilical hernia with liver cirrhosis and ascites. Int J Surg 12(2): 181-185.

14. Gurită RE, Popa F, Bălălău C, Scăunasu RV (2013) Umbilical hernia alloplastic dual-mesh treatment in cirrhotic patients. J Med Life 6(1): 99-102. 
15. Belli G, D’Agostino A, Fantini C, Cioffi L, Belli A, et al. (2006) Laparoscopic incisional and umbilical hernia repair in cirrhotic patients. Surg Laparosc Endosc Percutan Tech 16(5): 330-333.

16. Triantos CK, Kehagias I, Nikolopoulou V, Burroughs AK (2011) Surgical repair of umbilical hernias in cirrhosis with ascites. Am J Med Sci 341(3): 222-226.

17. Belghiti J, Durand F (1997) Abdominal wall hernias in the setting of cirrhosis. Semin Liver Dis 17(3): 219-226.
18. Telem DA, Schiano T, Divino CM (2010) complicated hernia presentation in patients with advanced cirrhosis and refractory ascites: management and outcome. Surgery 148(3): 538543.

19. Fagan SP, Awad SS, Berger DH. Management of complicated umbilical hernias in patients with end-stage liver disease and refractory ascites. Surgery 135(6): 679-682.

20. Ginsburg BY, Sharma AN (2006) Spontaneous rupture of an umbilical hernia with evisceration. J Emerg Med 30: 155-157.

\section{Your next submission with Juniper Publishers will reach you the below assets}

- Quality Editorial service

- Swift Peer Review

- Reprints availability

- E-prints Service

- Manuscript Podcast for convenient understanding

- Global attainment for your research

- Manuscript accessibility in different formats

( Pdf, E-pub, Full Text, Audio)

- Unceasing customer service

Track the below URL for one-step submission https://juniperpublishers.com/online-submission.php 